\title{
Analisis Hubungan Higiene Perorangan dengan Kejadian Kecacingan Siswa Siswi SDN Barombong Kota Makassar
}

\author{
Fitriani Kahar \\ Polteknik Kesehatan, Kementrian Kesehatan, Semarang. \\ Email: fitrianikahar555@gmail.com
}

\begin{abstract}
(C) 2018 - UEJ Program Studi Pendidikan Kependudukan dan Lingkungan Hidup Universitas Negeri Makassar. Ini adalah artikel dengan akses terbuka dibawah Licensi CC BY-NC-4.0 (http:/creativecommons.org/licenses/by-nc/4.0)
\end{abstract}

\begin{abstract}
.
This study aims to find out (1) hand washing related to the worm incidence of Makassar elementary school students, (2) nail hygiene associated with the incidence of helminthiasis in Makassar city elementary school students, (3) the use of footwear related to the incidence of helminthiasis in Makassar elementary school students , (4) the factors most associated with the incidence of helminthiasis in students of the elementary school in Makassar. The method used was analytic observational and laboratory with cross sectional design. The location of the study was carried out at Barombong Elementary School in Makassar City. The analysis used was Chi square then continued with logistic regression. The results of this study indicate that (1) hand washing is related to the incidence of helminthiasis in students of the Barombong Elementary School in Makassar City with a value $(p=0.011)$, (2) Nail hygiene associated with the incidence of helminthiasis in Makassar Barombong Elementary School students with a value ( $p=$ 0.021), (3) The use of footwear is not related to the incidence of helminthiasis in students of Barombong Elementary School in Makassar City with a value $(p=0.362)$, (4) hand washing is the variable most associated with Exp value $(B)=8.554$. This study suggests the need for counseling and providing information to students about the need for individual hygiene, and the dangers of worm disease to prevent worm disease.
\end{abstract}

Keywords: Individual Hygiene, Worms, Elementary School Students.

\section{PENDAHULUAN}

Infeksi cacing adalah salah satu penyakit yang palig umum tersebar dan menjangkiti banyak manusia di seluruh dunia. Sampai saat ini penyakit-penyakit cacing masih tetap merupakan suatu masalah karena kondisi sosial dan ekonomi di beberapa bagian dunia. Pada umumnya, cacing jarang menimbulkan penyakit serius tetapi dapat menyebabkan gangguan kesehatan kronis yang berhubungan dengan faktor ekonomis. (Zulkoni, 2011)

Cacing bukanlah masuk golongan mikroba yang bersel satu dan tidak membutuhkan mikroskop untuk melihatnya. Cacing adalah mahluk yang bersel banyak, yang umumnya badannya panjang ada yang jelas bagian kepalanya dan ekor dan juga tidak jelas letak kepalanya, akan tetapi bila diteliti lebih jauh maka terlihat bahwa ekor dan kepala itu ada perbedaanya, bahwa pada ujung kepala terdapat mulut dan alat-alat penghisap, yang merupakan gigi dan lain sebagainya. Cacing, terutama cacing dewasa menimbulkan penyakit dan gangguan penyakit dan gangguan kesehatan kepada manusia. (Adam, 1995)

Cacing dalam tubuh manusia akan hidup, mendapatkan perlindungan dan menerima makanan dari menusia itu sebagai hospes. Cacing menyerap nutrisi dari tubuh manusia yang ditumpanginya, penyerapan nutrisi ini akan menyebabkan kelemahan dan penyakit.(Zulkoni, 2011). Kejadian cacingan tidak hanya terjadi pada anak-anak tapi juga terjadi pada kalangan remaja maupun orang dewasa apabila orang tersebut tidak menjaga higiene pribadi danlingkungannya. Pada anak-anak cacing akan 
UNM Environmental Journals, Vol. 2 No. 1 Desember 2018 hal. $12-17$

berdampak pada gangguan kemampuan untuk belajar, dan pada orang dewasa akan menurunnya produktifitas kerja. Dalam jangka panjang, hal ini akan berakibat menurunnya kualitas sumber daya manusia.

Begitu banyak kerugian yang akan timbul sebagai akibat infeksi cacing. Melihat kenyataan ini maka program penanggulangan infeksi cacing, terutama pada usia anak sekolah merupakan masalah yang cukup serius. Penyakit cacing merupakan penyakit infeksi yang menular dari mahluk hidup lain ke mahluk hidup lainnya, hal itu tidak terlepas dari beberapa faktor diantaranya ; migrasi penduduk, lalu lintas, kepariwisataan, keberadaan fektor penyakit, hygiene perorangan ataupun menyeluruh, prilaku hidup, factor ekonomi, dan lain sebagainya.

Sekolah dasar negeri barombong merupakan sekolah yang mempunyai sarana dan prasarana yang memadai yang terdiri dari 6 kelas dan jumlah siswanya \pm 500 sisswa. Terdapat lapangan yang cukup luas dimana untuk tempat bermain anak-anak yang bersentuhan langsung dengan tanah pada saat bermain. Kita ketahui bahwa letak sekolah dasar negeri barombong makassar berada di dekat jalan raya yang berpolusi dan di depan sekolah tersebut terdapat sebuah puskesmas dan kantor lurah barombong. Dan disekitar sekolah tersebut banyak terdapat jajanan pinggir jalan seperti penjual siomai, empek-empek, es putar, cendol, dan lain-lain.

Aktivitas keseharian para siswa sebagaimana mestinya yang diarahkan oleh para guru diruangan dan di luar kelas para siswa bermain di lapangan yang memang kegemaran anak-anak seperti main bola kaki, main kasti dan lain-lain. Setelah bermain mereka membeli jajanan di samping sekolah seperti yang disebutkan di atas, dan para siswa biasanya tidak memperhatikan kebersihannya sebelum mengkonsumsi makanan.

Higiene perorangan mengacu kepada kebersihan tubuh perseorangan. Manusia merupakan sumber potensial mikroorganisme yang dapat menyebabkan penyakit pada manusia. Usaha higiene perorangan di rumah dilakukan setiap hari. Kebiasaan mencuci tangan sebelum makan , gosok gigi, mandi dengan sabun, penggunaan alas kaki, dan menjaga kebersihan kuku adalah bagian dari higiene perorangan yang bisa berhubungan dengan kejadian kecacingan pada siswa siswi SDN Barombong Kota Makassar. Dalam kesempatan ini penulis ingin melakukan penelitian analisis hubungan higiene perorangan dengan kejadian kecacingan pada siswa siswi SDN Barombong Kota Makassar.

\section{METODE}

Penelitian ini merupakan jenis penelitian observasional analitik dan laboratorium dengan desain cross sectional. Penelitian ini dilaksanakan pada SDN Barombong Kota Makassar. Sampel adalah murid SD Negeri Barombong sebanyak 50 orang dengan tekhnik pengambilan sampel secara purposive sampling. Pengumpulan data dilakukan melalui pemeriksaan sampel, observasi langsung dan wawancara serta pengisian kuisioner terhadap siswa. Analisis data dilakukan dengan menggunakan SPSS 21. Analisis data dilakukan terhadap data primer dengan menggunakan perhitungan statistik.

\section{HASIL DAN PEMBAHASAN}

\section{Hubungan Kebiasaan Cuci Tangan Dengan Kecacingan}

Tabel 3.1 Hubungan Kebiasaan Cuci Tangan Dengan Kecacingan Pada Murid SDN Barombong

\begin{tabular}{|c|c|c|c|c|c|c|}
\hline \multirow{3}{*}{ Cuci Tangan } & \multicolumn{4}{|c|}{ Kecacingan } & \multirow{2}{*}{\begin{tabular}{c}
\multirow{2}{*}{$\begin{array}{c}\mathrm{X}^{2} \\
\text { Total }\end{array}$} \\
\cline { 2 - 5 }
\end{tabular}} & \multicolumn{3}{|c|}{ Positif } & \multicolumn{2}{c|}{ Negatif } & & \\
\cline { 2 - 5 } & $\mathrm{N}$ & $\%$ & $\mathrm{~N}$ & $\%$ & & \\
\hline Tidak Baik & 8 & 66,7 & 4 & 33,3 & 12 & 6,4 \\
\hline Baik & 10 & 26,3 & 28 & 73,7 & 38 & $(0,011)$ \\
\hline Total & 18 & 36,0 & 32 & 64,0 & 50 & \\
\hline
\end{tabular}

Sumber: Data Primer

Tabel 3.1 menunjukkan bahwa dari 12 sampel yang menyatakan kebiasaan mencuci tangan yang tidak baik, 8 orang $(66,7 \%)$ diantaranya positif terinfeksi kecacingan dan 4 orang $(33,3 \%)$ negatife terinfeksi kecacingan. Dari 38 sampel yang menyatakan kebiasaan mencuci tangan yang baik, 10 orang 
(26,7\%), diantaranya positif terinfeksi kecacingan dan 28 orang $(73,7 \%)$ negatif terinfeksi kecacingan.

Hasil uji statistik dengan chi square diperoleh nialai $\mathrm{p}=0,011(\mathrm{p}<0,05)$ yang berarti ada hubungan yang signifikan antara kebiasaan mencuci tangan dengan kejadian kecacingan.

\section{Hubungan Kebersihan Kuku Dengan Kecacingan}

Tabel 3.2 Hubungan Kebersihan Kuku Dengan Kecacingan Pada Murid SDN Barombong

\begin{tabular}{|c|c|c|c|c|c|c|}
\hline \multirow{3}{*}{ Kebersihan Kuku } & \multicolumn{4}{|c|}{ Kecacingan } & \multirow{3}{*}{ Total } & \multirow{3}{*}{$\begin{array}{l}\mathrm{X}^{2} \\
(\mathrm{P})\end{array}$} \\
\hline & \multicolumn{2}{|c|}{ Positif } & \multicolumn{2}{|c|}{ Negatif } & & \\
\hline & $\mathrm{N}$ & $\%$ & $\mathrm{~N}$ & $\%$ & & \\
\hline Tidak Baik & 9 & 60,0 & 6 & 40,0 & 15 & 5,3 \\
\hline Baik & 9 & 25,7 & 26 & 74,3 & 35 & $(0,021)$ \\
\hline Total & 18 & 36,0 & 32 & 64,0 & 50 & \\
\hline
\end{tabular}

Sumber : Data Primer

Tabel 3.2 menunjukkan bahwa dari 15 sampel yang menyatakan kebersihan kuku yang tidak baik, 9 orang $(60 \%)$ diantaranya positif terinfeksi kecacingan dan 6 orang $(40 \%)$ negatife terinfeksi kecacingan. Dari 35 sampel yang menyatakan kebersihan kuku yang baik, 9 orang $(25,7 \%)$, diantaranya positif terinfeksi kecacingan dan 26 orang $(74,3 \%)$ negatif terinfeksi kecacingan.

Hasil uji statistik dengan chi square diperoleh nialai $\mathrm{p}=0,021(\mathrm{p}<0,05)$ yang berarti ada hubungan yang signifikan antara kebersihan kuku dengan kejadian kecacingan

\section{Hubungan Penggunaan Alas Kaki Dengan Kecacingan}

Tabel 3.3 Hubungan Penggunaan Alas Kaki Dengan Kecacingan Pada Murid SDN Barombong

\begin{tabular}{|c|c|c|c|c|c|c|}
\hline \multirow{2}{*}{$\begin{array}{c}\text { Penggunaan Alas } \\
\text { kaki }\end{array}$} & \multicolumn{4}{|c|}{ Kecacingan } & \multirow{2}{*}{ Total } & \multirow{2}{*}{\begin{tabular}{|}
$\mathrm{X}^{2}$ \\
$(\mathrm{P})$
\end{tabular}} \\
\cline { 2 - 5 } & \multicolumn{2}{|c|}{ Positif } & \multicolumn{2}{c|}{ Negatif } & & \\
\cline { 2 - 5 } & $\mathrm{N}$ & $\%$ & $\mathrm{~N}$ & $\%$ & & \\
\hline Tidak Baik & 3 & 25,0 & 9 & 75,0 & 12 & 0,82 \\
\hline Baik & 15 & 39,5 & 23 & 60,5 & 38 & $(0,362)$ \\
\hline Total & 18 & 36,0 & 32 & 64,0 & 50 & \\
\hline
\end{tabular}

Sumber: Data Primer

Tabel 3.3 menunjukkan bahwa dari 12 sampel yang menyatakan penggunaan alas kaki yang tidak baik, 3 orang (25\%) diantaranya positif terinfeksi kecacingan dan 9 orang $(75,0 \%)$ negatif terinfeksi kecacingan. Dari 38 sampel yang menyatakan penggunaan alas kaki yang baik, 15 orang $(39,5 \%)$, diantaranya positif terinfeksi kecacingan dan 23 orang $(60,5 \%)$ negatif terinfeksi kecacingan.

Hasil uji statistik dengan chi square diperoleh nialai $\mathrm{p}=0,362(\mathrm{p}>0,05)$ yang berarti tidak ada hubungan yang signifikan antara penggunaan alas kaki dengan kejadian kecacingan.

\section{Faktor Yang Berhubungan Dengan Kecacingan}

Tabel 3.4 Analisis Regresi Logistik Faktor Yang Berhubungan Dengan Kecacingan Pada Murid SD

\begin{tabular}{|c|c|c|c|c|}
\hline Sampel & B & Df & Sig & $\operatorname{Exp(B)}$ \\
\hline Kebiasaan Cuci Tangan & 2,146 & 1 & 0,008 & 8,554 \\
\hline Kebersihan Kuku & 1,889 & 1 & 0,012 & 6,610 \\
\hline
\end{tabular}

Sumber : Data Primer 
Tabel 3.4 menunjukkan bahwa dari kedua variabel independen yang berhubungan (kebiasaan cuci tangan,dan kebersihan kuku) maka didapatkan hasil variabel yang paling berhubungan yaitu cuci tangan dengan nilai $\operatorname{Exp}(B)=8,554$, kemudian kebersihan kuku dengan nilai $\operatorname{Exp}(B)=6,610$.

\section{Pembahasan}

\section{Hubungan antara kebiasaan cuci tangan dengan kejadian kecacingan}

Hasil uji statistik dengan chi square diperoleh nilai $p=0,011(\mathrm{p}<0,05)$ yang berarti ada hubungan yang signifikan antara kebiasaan mencuci tangan dengan kejadian kecacingan. Dari 50 orang murid menunjukkan bahwa dari 12 sampel yang menyatakan kebiasaan mencuci tangan yang Tidak Baik baik, 8 orang $(66,7 \%)$ diantaranya positif terinfeksi kecacingan dan 4 orang $(33,3 \%)$ negatif terinfeksi kecacingan. Dari 38 sampel yang menyatakan kebiasaan mencuci tangan yang baik, 10 orang $(26,7 \%)$, diantaranya positif terinfeksi kecacingan dan 28 orang $(73,7 \%)$ negatif terinfeksi kecacingan. Setelah dilakukan uji multivariate (regresi logistik) menunjukkan faktor kebiasaan cuci tangan adalah variabel yang paling dominan berhubungan dengan kejadian kecacingan.

Hasil penelitian ini mendukung penelitian Evi Yulianto (2007) di Semarang, bahwa ada hubungan yang signifikan antara kebiasaan cuci tangan dengan kejadian kecacingan. Menurut Majid (2001), bahwa cara yang paling baik dalam memutus mata rantai penularan infeksi kecacingan yang ditularkan melalui tanah, antara lain dengan menjaga kebersihan pribadi misalnya mencuci tangan dengan sabun sebelum makan dan menggunting kuku secara rutin.

Menurut Evi Yulianto (2007) telur cacing gelang keluar bersama tinja pada tempat yang lembab dan tidak terkena sinar matahari. Telur tersebut menjadi infektif. Infeksi cacing gelang terjadi bila telur yang infektif masuk melalui mulut bersama makanan atau minuman dan dapat pula melalui tangan yang kotor (Keputusan Menteri Kesehatan Nomor : 424/MENKES/SK/IV/2006).

Anak-anak paling sering terserang penyakit cacingan karena biasanya jari-jari tangan mereka dimasukkan ke dalam mulut, atau makan nasi tanpa cuci tangan, namun demikian orang dewasa juga dapat terserang penyakit cacingan. Cacing yang paling sering ditemui ialah cacing gelang, cacing tambang, cacing benang, cacing pita, dan cacing kremi (E.Oswari, 1991).

\section{Hubungan antara kebersihan kuku dengan kejadian kecacingan}

Hasil uji statistik dengan chi square diperoleh nialai $\mathrm{p}=0,021(\mathrm{p}<0,05)$ yang berarti ada hubungan yang signifikan antara kebersihan kuku dengan kejadian kecacingan. Dari 50 orang murid menunjukkan bahwa dari 15 sampel yang menyatakan kebersihan kuku yang Tidak Baik baik, 9 orang $(60 \%)$ diantaranya positif terinfeksi kecacingan dan 6 orang (40\%) negatife terinfeksi kecacingan. Dari 35 sampel yang menyatakan kebersihan kuku yang baik, 9 orang $(25,7 \%)$, diantaranya positif terinfeksi kecacingan dan 26 orang $(74,3 \%)$ negatif terinfeksi kecacingan.

Setelah dilakukan uji multivariate (regresi logistik) menunjukkan faktor kebersihan kuku merupakan variabel yang berhubungan dengan kejadian kecacingan. Hasil penelitian ini mendukung penelitian Jalaluddin (2008) di Lhokseumawe, bahwa ada hubungan yang signifikan antara kebersihan kuku dengan kejadian kecacingan. Infeksi kecacingan dapat dipengaruhi oleh karena murid sering bermain di tanah, sehingga lebih mudah terinfeksi kecacingan. Higiene perorangan seperti kebersihan kuku merupakan salah satu faktor yang berperan dalam terinfeksi kecacingan. Sebagian sampel yang tidak menjaga kebersihan kuku dan kuku kotor kemungkinan disebabkkan karena ketidaktahuan sampel. Infeksi kecacingan kebanyakan ditularkan melalui tangan yang kotor, kuku jemari tangan yang kotor dan panjang sering tersimpan telur cacing, jika kuku jemari tangan tidak dicuci dengan bersih maka telur cacing akan tersimpan dikuku akan ikut tertelan sewaktu makan (Nadesul, 1997).

Menurut Azwar (1993) pada prakteknya upaya higiene antara lain meminum air yang sudah direbus sampai mendidih, mandi dua kali sehari, mengambil makanan dengan memakai alat seperti sendok atau penjepit dan menjaga kebersihan kuku serta memotongnya apabila panjang. Kebersihan perorangan penting untuk pencegahan, kuku sebaiknya selalu dipotong pendek untuk menghindari penularan cacing dari tangan ke mulut (Srisasi gandahusada, 2000). 


\section{Hubungan antara penggunaan alas kaki dengan kejadian kecacingan}

Hasil uji statistik dengan chi square diperoleh nialai $\mathrm{p}=0,362(\mathrm{p}>0,05)$ yang berarti tidak ada hubungan yang signifikan antara penggunaan alas kaki dengan kejadian kecacingan. Dari 50 murid menunjukkan bahwa dari 12 sampel yang menyatakan penggunaan alas kaki yang Tidak Baik baik, 3 orang $(25 \%)$ diantaranya positif terinfeksi kecacingan dan 9 orang $(75,0 \%)$ negatif terinfeksi kecacingan. Dari 38 sampel yang menyatakan penggunaan alas kaki yang baik, 15 orang (39,5\%), diantaranya positif terinfeksi kecacingan dan 23 orang $(60,5 \%)$ negatif terinfeksi kecacingan.

Penggunaan alas kaki yang baik oleh murid sekolah dasar merupakan salah satu upaya untuk menurunkan jumlah penyakit kecacingan pada anak. Lapangan bermain anak yang sudah tidak kontak langsung dengan tanah merupakan salah satu faktor yang memungkinkan anak tidak terinfeksi kecacingan Apabila dilihat dari perilaku bermain kebanyakan murid bermain tanpa melepas alas kaki atau tetap memakai sepatu, yang merupakan salah satu penyebab anak tidak terinfeksi oleh penyakit kecacingan.

\section{KESIMPULAN DAN SARAN}

Berdasarkan hasil penelitian yang telah dilakukan tentang Analisis Hubungan Higiene Perorangan Dengan Kejadian Kecacinngan Pada Murid SDN Barombong Kota Makassar, maka dapat disimpulkan sebagai berikut :

1. Kebiasaan cuci tangan berhubungan dengan kejadian kecacingan pada murid SDN Barombong Kota Makassar

2. Kebersihan Kuku berhubungan dengan kejadian kecacingan pada murid SDN Barombong Kota Makassar

3. Penggunaan alas kaki tidak berhubungan dengan kejadian kecacingan pada murid SDN Barombong Kota Makassar

4. Variabel kebiasaan cuci tangan merupakan variabel yang paling berhubungan dengan kejadian kecacingan.

Adapun sarannya (1) Perlu diadakan program pencegahan dan pengobatan penyakit cacingan oleh pemerintah setempat, (2) Perlunya penyuluhan serta pemberian informasi kepada siswa tentang perlunya higiene perorangan, dan bahaya penyakit cacing guna pencegahan penyakit cacing, (3) Peningkatan kerjasama antara kepala sekolah dan guru untuk member bimbingan, pengarahan tentang higiene perorangan dan sanitasi lingkungan kepada siswa dalam upaya menurunkan prevalensi penyakit cacingan, dan (4) Diharapkan peran serta orang tua dalam usaha pencegahan dan pengobatan penyakit cacing.

\section{Referensi}

Adam Syamsir. Dasar dasar mikrobiologi parasitologi untuk perawat. Jakarta :EGC. 1992.

Departemen Kesehatan R.I. 2001. Pedoman Modul Dan Materi Pelatihan "Dokter Kecil”. Jakarta. Depkes RI.

Entjang Indan. 2003. Mikrobiologi Dan Parasitologi. PT. Citra Aditya. Bandung.

Entjang. I, 2003. Mikrobiologi dan Parasitologi untuk Akademi Keperawatan, Citra Aditya Bakti, Bandung.

Gandahusada Srisasi dkk . 1998. Prasitologi Kedokteran. Jakarta : fakultas Kedokteran Universitas Indonesia

Gandahusada Srisasi. 2000. Parasitologi Kedokteran edisi ke 3. Jakarta. EGC

Gandahusada Srisasi dkk. 2004. Parasitologi Kedokteran . Jakarta. FK UI

Irianto Koes. 2009. Parasitologi Berbagai Penyakit Yang Mempengaruhi Kesehatan Manusia. CV. YRAMA WIDYA. Bandung.

Jalaludddin, 2008. Pengaruh Sanitasi Lingkungan, Personal Hygiene, Dan Karakteristik Anak Terhadap Infeksi Kecacingan Pada Murid Sekolah Dasar Di Kecamatan Blang Mangat Kota Lhokseumawe. Disertasi, Program Pascasarjana USU. 
UNM Environmental Journals, Vol. 2 No. 1 Desember 2018 hal. $12-17$

Natadisastra Djaenudin dan Ridad Agoes. 2009. Parasitologi Kedokteran Ditinjau Dari Organ Tubuh Diserang. EGC. Jakarta

Natoatmodjo Soekidjo, 2005. Metodologi Penelitian Kesehatan. Jakarta. PT. Asdi Mahasatya

Natoatmodjo Soekidjo, 2007. Kesehatan Masyarakat Ilmu Dan Seni.Jakarta. PT RINEKA CIPTA

Natoatmodjo Soekidjo, 2007. Promosi Kesehatan Dan Ilmu Perilaku. Jakarta. PT RINEKA CIPTA

Natoatmodjo Soekidjo, 2010. Promosi Kesehatan Teori Dan Aplikasi.Jakarta. PT RINEKA CIPTA

Prasetia Heru. Atlas Berwarna Helmintologi Kedokteran. Airlangga Universiti Press. Surabaya.

Riwidikdo Handoko.2009. Statistik Untuk Penelitian Kesehatan Dengan Aplikasi Program $R$ dan SPSS. Pustaka Rihana. Jogja

Safar Rosdiana. 2010. Parasitologi Kedokteran Protozologi, Helmintologi, Entomologi. CV. YRAMA WIDYA. Bandung.

Sumanto Didik. 2010. Faktor Risiko Infeksi Cacing Tambang Pada Anak Sekolah. Universitas Dipenogoro.

Sutanto. I, dkk. 2008. Parasitologi Kedokteran, Edisi Keempat FKUI. Jakarta

Suyono dan budiman. 2011 Ilmu Kesehatan Masyarakat Dalam Konteks Kesehatan Lingkungan . Yogyakarta : EGC.

Yulianto Evi. 2007. Hubungan Higiene Sanitasi Dengan Kejadian Penyakit Cacingan Pada Siswa Sekolah Dasar Negeri Rowosari 01 Kecamatan Tembalang Kota Semarang. Universitas Negeri Semarang

Zulkoni H Akhisan. 2011. Parasitologi Untuk Keperawatan, Kesehatan Masyarakat dan Tehnik Lingkungan. Nuha Medika. Yogyakarta.

http://dhammacitta.com, Mitta. Kalyana, 2008. Gambaran Telur Cacing yang Menginfeksi Manusia, 15:10.

www.gogle.com. Rhayaqu.Arti Sikap.Senin, 12 januari 2009/diaakses tanggal 12 juli 2012

www.gogle.com.Yudi. Higiene Personal Dan Penanganan Pangan Yang Baik. 02 juli 2009/di akses pada tanggal 12 juli 2012. 